\title{
Prevalence of Hearing Loss and Tinnitus with Correlation to the Usage of Protective Hearing Equipment among Airport Workers
} \author{
Andejani ${ }^{1}$, Murad Al Momani ${ }^{2}$ and Abdulrahman Hagr ${ }^{1}$ \\ ${ }^{1}$ Otolaryngology Head and Neck Surgery Department, King Saud University, Saudi Arabia \\ ${ }^{2}$ Otolaryngology-Head and Neck Surgery Department, King Saud University, Saudi Arabia \\ ${ }^{3}$ Department of Otolaryngology, King Saud University, Saudi Arabia
}

Ahmed H Saleem ${ }^{1 *}$, Ghassan Alkharboush ${ }^{1}$, Othman Almazyed $^{1}$, Saud AlHilal ${ }^{1}$, Ibrahim Alnajashi ${ }^{1}$, Tawfeq Al

Submission: January 17, 2018; Published: January 30, 2018

*Corresponding author: Ahmed Hussain Saleem, Demonstrator in King Abdulaziz University, Jeddah, Saudi Arabia, Madinah, Saudi Arabia, Tel: 966502532000; E-mail: Ahmed.hs.saleem@gmail.com

Abstract

Objectives: Epidemiological studies have shown that tinnitus and occupational hearing loss are common symptoms in the working population. Only few studies have assessed the aforementioned symptoms in this population, none of which have assessed airport field workers, thus the need for our study.

Methodology: A cross-sectional study was conducted among airport field workers at King Khaled International Airport in Riyadh. The sample size was calculated to be 380 . Each was asked to fill a self-administered questionnaire and undergo pure tone audiometry to assess hearing level. The questionnaire assessed the participants' demographics, usage of protective hearing equipment (PHE) as well as prevalence and characteristics of tinnitus if present.

Results: Of all field workers, 300 (78\%) have agreed to participate in the study. A number of 180 (60\%) participants believe that PHE prevents noise-related hearing loss. Of all participants, 114 (38\%) of workers use PHE. No association was found between the participants' believe regarding PHE benefits and their usage of the equipment ( $\mathrm{P}=0.473)$. Tinnitus was reported by $81(27 \%)$ of the whole sample. Most of the participants $171(57 \%)$ were found to have hearing impairment ( $>25 \mathrm{~dB} \mathrm{HL})$ at low frequencies $(0.5,1,2 \mathrm{kHz})$, in comparison to $144(48 \%)$ at high frequencies ( 4 and $8 \mathrm{kHz}$ ).

Conclusion: Even with relatively good knowledge about the importance of PHE, only few workers actually use them. Thus, frequent audiometric screening tests as well as enforcement of PHE usage by airport field workers needs to be introduced by the airport administrations.

Keywords: Tinnitus; Occupational; Hearing loss; Airport workers; Protective hearing equipment

\section{Introduction}

Sound and noise are part of the same auditory continuum. Noise has been defined by the National Institute for Occupational Safety and Health as «any unwarranted disturbance within a useful frequency band» [1]. As a result of industrialization, noise exposure in different occupations is almost inevitable. Noise has been identified as a risk factor for multiple medical conditions including hypertension, anxiety, hearing loss and tinnitus [2,3] In fact, noise is responsible for $16 \%$ of hearing loss worldwide [4] In the United stated, approximately twenty-two million individuals are exposed to dangerous levels of noise each year [5]. Approximately 10 million individuals in the U.S suffer from occupational hearing loss [6] In Saudi Arabia (KSA), Ahmed et al. has shown that the prevalence of hearing impairment in industrial workers exposed to noise is $39.3 \%$ in comparison to only $4.5 \%$ of non-noise exposed worker [7]. These levels are comparable to China where $42 \%$ of airport maintenance workers are estimated to suffer from occupational hearing loss [8].

Tinnitus is defined as noise, regardless of its nature, perceived in absence of external stimulus, [9] This noise may take multiple forms such as whistling, buzzing or hissing and may be perceived as emanating from within the head or outside the body. The sound perceived may be subjective in nature, audible only by the patient, or objective, audible by both the patient and the examiner. Objective tinnitus is quite rare with a defined muscular or vascular pathology whereas subjective tinnitus is due to neurophysiological aberrations in the auditory pathway [9]. The prevalence of tinnitus differs globally. In Japan, $11.9 \%$ of adults (45-79) are reported to have tinnitus [10]. Similarly, 10\% of Industrial workers in KSA were found to have tinnitus [7]. In the most recent survey, Kim et al. [11] surveyed approximately 
twenty thousand adults aged between 20 and 98 and identified a prevalence of $20.7 \%$, of which $31 \%$ reported that they were annoyed by the noise during their daily life [11].

The study results showed that females were at a higher risk of developing tinnitus and that patients with depression are twice as likely to develop tinnitus when compared to the rest of the population. Other defined risk factors included, smoking, dyslipidemia, age and different systemic chronic diseases such as Rheumatoid arthritis and thyroid diseases [11]. In Saudi Arabia, only few studies have assessed the prevalence of hearing loss and tinnitus in the working population, none of which have assessed airport workers. We hope that our study can shed light on this topic in our community and provide feedback regarding possible educational programs or screening strategies, if needed, directed towards this population.

\section{Methods}

\section{Ethical statement}

The study protocol was approved by the institutional review board of King Saud University. The study was conducted in accordance with the Declaration of Helsinki. Informed consent was attained from all participants prior to their inclusion in this study.

\section{Study design}

A quantitative observational cross-sectional study

\section{Subjects}

King Khalid International Airport is the largest airport in the kingdom of Saudi Arabia with a total of 900 Airport Field Workers (AFWs) distributed across 3 departments: maintenance, transportation and cargo and is located in the capital city, Riyadh. In this cross-sectional study, we targeted all AFW working at King Khalid International Airport in the year 2016 to assess the prevalence of hearing Loss and tinnitus, and to correlate them with the use of protective hearing equipment. All AFWs included in this study have underwent a pre-employment baseline audiometry screening. Inclusion criteria included all AFWsat King Khalid International Airport. Exclusion criteria included refusal to participate.

\section{Sample size}

According to the airport administration office there were 900AFWs (Total population). Because fewstudies have assessed the prevalence of tinnitus among aircraft workers in the Middle East, we assumed that $50 \%$ currently suffer from tinnitus to achieve the maximum sample size. We considered a margin of error of $5 \%$, with a $95 \%$ confidence level. By using the standard sample size formula for a single proportion:

$$
\mathrm{N}=\mathrm{Z} 2 \alpha \mathrm{P}(1-\mathrm{P}) / \mathrm{d} 2
$$

N: Sample size

\section{P: Proportion. \\ d: Margin of error.}

$\mathbf{Z} \boldsymbol{\alpha}$ : A normal deviate reflects the type I error and is equal to 1.96 for $95 \%$ confidence level

Sample size was calculated to be 384 .

\section{Data collection tools}

A self-administered questionnaire was used to assess the study's objectives. Due to the study's multiethnic population, both English and Arabic languages of the questionnaire was used. The questionnaire was composed of 3 main parts. Part 1 assesses participants' demographics in terms of age, gender, nationality, educational status, years spent at the airport and usage of protective hearing equipment (PHE). Part 2 of the questionnaire addresses the prevalence of tinnitus and its characteristics. Presence or absence of tinnitus was determined by the following question «In the past 12 months, have you noticed any buzzing, ringing or any other form of noise in the absence of any external sound?». Tinnitus severity was assessed using a subjective scale of «mild», «moderate», or «severe» as well as its impact on sleep. Part 3 included formal audiometric testing. The testing took place in a secluded room approximately $0.5 \mathrm{~km}$ from runway to minimize interfering background noise. For the purpose of this study, hearing loss was divided into low $(0.5,1$, and $2 \mathrm{kHz})$ and high frequency ( 4 and $8 \mathrm{kHz}$ ). A hearing loss of mild corresponded to hearing difficulties between $(\geq 25$ and $\leq 40 \mathrm{~dB})$, moderate $(40-55 \mathrm{~dB})$ and severe $(>55 \mathrm{~dB})$.

\section{Statistical analysis}

Pilot study was conducted on the first week on 10 employees to assess the clarity of the questionnaire, time needed for data analysis as well as data cleaning. Categorical variables were reported as percentage while continuous variable was reported for means and standard deviation. Chi-square test was used to compare the participants'belief regarding PHE benefits and their usage of the equipment. The results were considered statistically significant if $\mathrm{P} \leq 0.05$. SPSS software version 21.0(41) was used for further analysis of data.

\section{Results}

\section{Demographics}

Three hundred airport workers responded to the survey yielding a response rate of $78 \%$. Our population consisted of male participants exclusively, as there are no female airport field workers in Saudi Arabia. Participants were of Saudi nationality (68\%), high-school graduates (38\%), aged between 30-39(37\%), and are current smokers (45\%). The demographics are summarized in (Table 1). In regards to years spent working in the airport: $40.3 \%$ of the respondents had worked at the airport for more than 10 years, $24 \%$ of the respondents had been employed for 1 to 3 years, $17.3 \%$ of the respondents had worked at the airport for 4 to 6 years; $11.7 \%$ of the respondents 
had worked at the airport for 7 to 9 years; and only $6.7 \%$ of the respondents had worked at the airport for less than 1 year.

Table 1: Demographics.

\begin{tabular}{|c|c|}
\hline Age & Percent \\
\hline$>20$ & $1.0 \%$ \\
\hline 20 to 29 & $33.3 \%$ \\
\hline 30 to 39 & $36.7 \%$ \\
\hline 40 to 49 & $20.0 \%$ \\
\hline 50 to 59 & 8.75 \\
\hline 60 to 69 & $0.3 \%$ \\
\hline$>70$ & $1.0 \%$ \\
\hline Education Status & Percent \\
\hline High School & $38.3 \%$ \\
\hline Diploma & $34.3 \%$ \\
\hline Bachelor & $24.3 \%$ \\
\hline Masters & $3.0 \%$ \\
\hline Total & $100 \%$ \\
\hline Smoking Status & Percent \\
\hline Current Smoker & $44.6 \%$ \\
\hline Former Smoker & $17.7 \%$ \\
\hline Never Smoked & $37.7 \%$ \\
\hline
\end{tabular}

\section{Usage of protective hearing equipment}

Only 38\% of surveyed sample reported using PHE during work, of whom: $50 \%$ use PHE for 1-3 hours/day, 27\% use it for 4-6 hours, $13 \%$ use it for 7-9 hours and only $10 \%$ reported using PHE all throughout their work shift. Furthermore, our survey shows that only $58 \%$ of our sample believe that PHE preventhearing loss. Only $45 \%$ believe that PHE prevent tinnitus.

\section{Prevalence and characteristic tinnitus}

Tinnitus was reported by $27 \%$ of population. In most cases, tinnitus was bilateral (61\%) and did not cause any difficulties in sleep (67\%). Tinnitus reportedly affected right ear in $19 \%$, left ear in $22 \%$ and was bilaterally in $59 \%$. Only $20 \%$ of those affected by tinnitus sought medical attention.

\section{Pure tone audiometry}

In the low frequency group $(0.5,1.2 \mathrm{kHz})$, a total of 43 participants were found to have some degree of hearing loss, most of whom (79\%) was measured at mild. In regards to high frequency hearing loss ( 4 and $8 \mathrm{kHz}$ ), 36 participants were found to have some degree of hearing loss, most of whom (50\%) was measured also at mild. Across all frequencies, 32 participants were found to have variable degree of hearing loss most of whom (69\%) was measured also at mild. These results are summarized in (Table 2). Possible risk factors for hearing loss were also assessed. The results of which are summarized in (Table 3).

Table 2: Audiometry Results

\begin{tabular}{|c|c|c|c|}
\hline \multirow{2}{*}{$\begin{array}{c}\text { Presence and } \\
\text { Degree }\end{array}$} & $\begin{array}{c}\text { Tow } \\
\text { Frequency } \\
(\mathbf{0 . 5}, \mathbf{1 , 2} \mathbf{~ k H z})\end{array}$ & $\begin{array}{c}\text { High } \\
\text { Frequency (4 } \\
\text { and 8 kHz) }\end{array}$ & $\begin{array}{c}\text { All frequency } \\
\mathbf{( 0 . 5 , 1 , 2 , 4 , 8} \\
\mathbf{~ k H z})\end{array}$ \\
\hline $\begin{array}{c}\text { No impairment } \\
(<25 \mathrm{~dB} \text { HL) }\end{array}$ & $257(85.7)$ & $268(89.4)$ & $265(88.3)$ \\
\hline $\begin{array}{c}\geq 25 \text { and } \leq 40 \\
\text { (mild) }\end{array}$ & $34(11.3)$ & $18(6.0)$ & $22(7.3)$ \\
\hline $\begin{array}{c}<40 \text { and } \leq 55 \\
\text { (moderate) }\end{array}$ & $5(1.7)$ & $9(3.0)$ & $7(2.3)$ \\
\hline$>55$ (severe) & $4(1.3)$ & $5(1.7)$ & $4(1.3)$ \\
\hline $\begin{array}{c}\text { Total with } \\
\text { impairment } \\
(\geq 25 \mathrm{~dB} \text { HL) }\end{array}$ & $43(14.3)$ & $36(12.0)$ & $32(10.9)$ \\
\hline
\end{tabular}

Table 3: Possible risk factors for hearing loss.

\begin{tabular}{|c|c|c|}
\hline \multirow{2}{*}{} & Yes & No \\
\cline { 2 - 3 } & Percent & Percent \\
\hline Ear Injury & $5.0 \%$ & $95.0 \%$ \\
\hline Head injury & $9.0 \%$ & $91.0 \%$ \\
\hline $\begin{array}{c}\text { Exposure to } \\
\text { explosions }\end{array}$ & $2.3 \%$ & $97.7 \%$ \\
\hline $\begin{array}{c}\text { Family history of } \\
\text { deafness }\end{array}$ & $2.0 \%$ & $98.0 \%$ \\
\hline
\end{tabular}

\section{Discussion}

This study represents the first study to assess the prevalence of tinnitus and hearing loss among AFWs and measuring their compliance in regards to the use of PHE in Saudi Arabia and probably the Middle East. Even though in our study we did not measure the level of noise at the airport field, based on the international and global scales of noise pollution, the maximum dose of environmental noise $(140 \mathrm{db})$ a person can receive is by being within 25 meters distance from an airplane take-off [12]. Unfortunately, few studies have been done in Saudi Arabia and the Middle East to evaluate the burden of NIHL and tinnitus in settings with high levels of noise.

\section{Usage of protective hearing equipment}

US National Institute for Occupational Safety and Health (NIOSH 1998) noted that effective use of hearing protective devices would reduce the rate of NIHL hearing loss in noiseexposed workers [13]. Previous studies assessing the compliance to PHE among individuals working at places with high levels of noise have generally documented low usage rates [14]. Lusk et al showed that the average usage rates of PHE among 400 construction workers is ranging from 18 to $49 \%$ [15]. In the present study, although $60 \%$ of the participants believe that PHE prevent hearing loss and $45 \%$ believe that they prevent tinnitus, only $38 \%$ actually use them. Moreover, no association was found between the participants' believe regarding PHE benefits and 
their usage of the equipment $(\mathrm{P}=0.373)$.

\section{Prevalence and characteristic of tinnitus}

Tinnitus is an early warning symptom for NIHL [5]. In a study done at South Korea by Song JB et al. [16] on manufacturing workers (noise exposure group) and design workers (control group) at shipyard, tinnitus prevalence was $24.3 \%$ and $3.6 \%$ [17]. This study demonstrated the relationship between the high levels of noise and tinnitus.It is worth mentioning that the severity of hearing loss was found to be significantly higher in workers with tinnitus compared to workers without tinnitus in the aforementioned study. In our study, the prevalence of tinnitus was $27 \%$ with the majority of the participants (61\%) reporting bilateral tinnitus. Conversely, a similar study done in eastern Saudi Arabia demonstrated that the prevalence of tinnitus among 269 industrial workers is 11\% [7]. It included workers at steel pipes and the other manufactured air conditioning units. Tinnitus due to noise exposure is drawing less attention than NIHL. Nevertheless, the probability of tinnitus development ought to be taken into consideration in hearing preservation programs for the high association reported between noise exposure and tinnitus.

\section{Pure tone audiometry}

Occupational NIHL hearing lossoccurs among individuals that are exposed to excessive amounts of noise for long durations [18]. In a study done at the Republic of China by Chen TJ et al. [8] on 112 airport employees, the prevalence of high-frequency hearing loss was $41.9 \%$. While at Jomo Kenyatta International Airport in Nairobi, the prevalence of NIHL was 15.3\% [18]. Similarly, in the present study done at King Khalid international airport, the prevalence of NIHL was found to be $12 \%$. Several factor can contribute the the disparity of the aforementioned results including duration of exposure to noise as well as the compliance to the PHE. That is concerning NIHL among airport workers. On the other hand, a fair percentage of studies have been published in the literature to assess NIHL among workers exposed to high levels of noise. One of which is a study done in Saudi Arabia by Ahmed et al involving 259 industrial workers (one manufactured steel pipes and the other is air conditioning unit) found that the prevalence of high frequency hearing loss is $65.6 \%$. Nevertheless, the usage of PHE or the duration of exposure to noise were not documented [7]. In addition, a periodic annual audiometric examination in Taiwan done by $\mathrm{Wu}$ TN et al on a large number of noise exposed workers $(9,535)$ showed that a total of 3,216 (34.0\%) workers were found to have NIHL. In our target population, we found that the airport administration does encourage AFW do undergo an annual audiometric screening; although there was no official surveillance system to screen for NIHL among AFW.

\section{Conclusion}

Even with relatively good knowledge about the importance of PHE, only few workers actually use them. Thus, frequent audiometric screening tests as well as enforcement of PHE usage by airport field workers needs to be introduced by the airport administrations.

\section{References}

1. NIOSH (1991) Noise-induced loss of hearing. Cincinnati, OH, National Institute for Occupational Safety and Health.

2. Jarup L, Babisch W, Houthuijs D, Pershagen G, Katsouyanni K, et al (2008) Hypertension and exposure to noise near airports: the HYENA study. Environ Health Persp 116: 329-333

3. Beutel ME, Junger C, Klein EM, Wild P, Lackner K et al. (2016) Noise annoyance is associated with depression and anxiety in the general population-the contribution of aircraft noise. PLoS One 11(5): e0155357.

4. Tak S, Davis RR, Calvert GM (2009) Exposure to hazardous workplace noise and use of hearing protection devices among US workersNHANES. Am J Ind Med 52: 358-371.

5. Nelson DI, Nelson RY, Concha-Barrientos M, Fingerhut M (2005) The global burden of occupational noise-induced hearing loss. Am J Ind Med 48(6): 446-458.

6. Petersen R (2017) Centre for Disease Control. Breastfeed Med 12(8):465-467.

7. Ahmed HO, Dennis JH, Badran O, Ismail M, Ballal SG, et al. (2001) Occupational noise exposure and hearing loss of workers in two plants in Eastern Saudi Arabia. Annals Occup Hyg 45(5): 371-380.

8. Chen TJ, Chiang HC, Chen SS (1992) Effects of aircraft noise on hearing and auditory pathway function of airport employees. J Occup Med 34(6): 613-9.

9. Han BI, Lee HW, Kim TY, Lim JS, Shin KS (2009) Tinnitus: characteristics, causes, mechanisms, and treatments. J Clin Neurol 5: 11-19.

10. Fujii K, Nagata C, Nakamura K, Kawachi T, Takatsuka N et al. (2011) Prevalence of tinnitus in community dwelling Japanese adults. J Epidemiol 21: 299-304.

11. Kim HJ, Lee HJ, An SY, Sim S, Park B et al., (2015) Analysis of the Prevalence and Associated Risk Factors of Tinnitus in Adults. PLoS One 10(5): e0127578.

12. Yuen FK (2014) A vision of the environmental and occupational noise pollution in Malaysia. Noise Health 16(73): 427-36.

13. NIOSH (1998) Criteria for a Recommended Standard: Occupational Noise Exposure. Revised Criteria National Institute for Occupational Safety and Health, Cincinnati.

14. Edelson J, Neitzel R, Meischke H, et al., (2009) Predictors of Hearing Protection Use in Construction Workers. Annals of Occupational Hygiene 53(6): 605-615.

15. Lusk SL, Kerr MJ, Kauffman SA (1998) Use of hearing protection and perceptions of noise exposure and hearing loss among construction workers. Am IndHygAssoc J 59: 466-70.

16. Song JB, Kim BK (2002) Prevalence and characteristics of tinnitus in noise exposed workers. Occup Health 6:16-28.

17. Anino JO, Afullo A, Otieno F (2010) Occupational noise-induced hearing loss among workers at Jomo Kenyatta International Airport, Nairobi. East Afr Med J 87(2): 49-57.

18. Wu TN, Liou SH, Shen CY, Hsu CC, Chao SL et al. (1998) Surveillance of noise-induced hearing loss in Taiwan, ROC: a report of the PRESS-NHL results. Prev Med 27(1): 65-69. 
(C) (i) This work is licensed under Creative DOI: $10.19080 /$ GJO.2018.13.555860
Your next submission with Juniper Publishers will reach you the below assets

- Quality Editorial service

- Swift Peer Review

- Reprints availability

- E-prints Service

- Manuscript Podcast for convenient understanding

- Global attainment for your research

- Manuscript accessibility in different formats

( Pdf, E-pub, Full Text, Audio)

- Unceasing customer service

Track the below URL for one-step submission https://juniperpublishers.com/online-submission.php 